\title{
Surveillance and Morality: Revisiting the Education Reform Act (1988) in the United Kingdom
}

\author{
J ason L Powell1 and Margaret Edwards²
}

\begin{abstract}
Recently, there has been an increased interest in British educational provision arising form the consequences of the Education Reform Act (1988). The ERA was pivotal insofar as it precipitated what has been a relentless neo-liberal political campaign to legitimise 'choice' for parents and place 'power' within Schools. However, the use of school technologies that focus on 'assessment' and 'inspection', can, in this policy climate, become a means of surveillance and enforcement of morality and educational practice in the United Kingdom. Smart (1985) argues that the work of Michel Foucault (1977) can be characterised as 'neo-Marxist' and subsequently offers a set of theoretical strategies for understanding how policy discourses on education construct and control children's experiences and their identities, as constructed objects/subjects of knowledge.
\end{abstract}

\section{Introduction}

This paper deconstructs the hagiography surrounding British education and provides a critical analysis of Education Reform Act (ERA) (1988) grounded in Foucauldian insights. Barry Smart (1985) makes the contentious point that Michel Foucault's theoretical insights can be labelled as 'neo-Marxist' in highlighting how surveillance is a critical feature of modern education policy and schools. Whilst traditional Marxist scholarship has an awareness of economics and ideology in the context of social relationships in education; a neo-Marxist perspective grounded in Foucault's work can illustrate how surveillance and discourses of power impact the positioning of children as educational objects of control, domination and subordination. It would be wrong to deny the impact of 'subjectivity' as a core concept in the process of education (Ball, 1990; Powell and Edwards, 2003). However, in offering an alternative and critical exploration of ERA we can address C.W. Wright Mills (1959) powerful argument that sociological theorising must

\footnotetext{
${ }^{1}$ Department of Sociology, Social Policy and Social Work Studies, University of Liverpool, UK. mailto:Jasonpwll@aol.com

2 Director of School of Social Science, Liverpool John Moores University, UK. mailto:m.m.Edwards@livjm.ac.uk
} 
focus on how individual biographies are shaped by the wider social forces within a particular period in history and culture. Similarly, Fairclough (1992) suggests that a critical perspective opens up 'common sense assumptions' that lie at the heart of western culture about social institutions. Fairclough (1992) further suggests that Foucault's (1967) work on 'discourse' has similarities with the Gramscian concept of "hegemony". This assertion is evidenced by Foucault (1984:110) himself, when he states, 'Discourse in not simply that which translates struggles or systems of domination, but is the thing for which there is struggle. Discourse is the power to be seized."

Nevertheless, there are certainly tensions between Foucault's neo-Marxism and variants of structuralist Marxism. Foucault side-steps the binary relationship set up by the Marxist educational theory of Bowles and Gintis (1976) for example, between true and false realities, ways of knowing and political consciousness. Foucault has the theoretical reflexivity of loosening knowledge, ideas and subject positions from categories of social totality, such as social formation, the mode of production, history, economy and society (Ball, 1990). Thus suspended from their ostensible connections, social ideas are re-articulated in Foucault's thought to historical and societal features ignored in Marxist models of social reality based on the labour process and modes of economic exploitation. Hence, Foucault's neo-Marxist perspective on discourse, power and surveillance provides a rich seam of theorizing as an addition to Marxist scholarship (Smart, 1985). Indeed, whereas Marxism has focused on the 'macrophysics of power' (Powell and Edwards, 2002), Foucault's (1977) work complements such an approach by focusing on the 'microphysics of power'; relationships between social actors and institutions. Coupled with this, Granovetter (1985) stressed the importance of linked socially embedded networks as a way of theorizing relations between macrostructures and microlevels of action. Thus:

Actors do not behave or decide as atoms outside a social context, nor do they adhere slavishly to a script written for them by the intersection of social categories that they happen to occupy. Their attempts at purposive action are instead embedded in concrete, ongoing systems of social relations. (Granovetter, 1985: 487)

For Granovetter (1992) economic institutions do not emerge automatically, instead, they are socially constructed by power relations between individuals and structural manifestations of social control. Hence, Smart (1985) stresses the importance of widening Marxist insights to include other conflict approaches such as those derived from the critical scholarship of Foucault.

The substantive focus of this paper will be to identify how the generic concerns of British educational policy have legitimised surveillance practices. Simplistically, this idea can be presented as a mathematical metaphor of 'inspection - intervention $=$ surveillance'. It also serves to illuminate otherwise hidden facets affecting secondary education, which while based on foundational concerns, can unwittingly serve more adverse purposes. Indeed, a cogent examination of ERA (1988) raises serious questions about its main political intentions. It is important to note that ERA failed to convey in any strong sense alternative definitions of truth or different visions of educational truth based on children's subjective experiences (Ball, 1990). Rather, the ageism of educational policy directs its gaze downwards towards children, thus 
reinforcing "an overall impression that these are the people who need to be researched, these are the ones who are out of step with "social norms" or who are causing the problems" (Smart 1984:150-1). Conversely, educational policy rarely gazes upwards to look at "the locally powerful" (Smart, 1984:33) who in the case of children would be head-teachers as managers. The lack of any critical analysis of the role and daily practices of head-teachers constitutes a major weakness of political discourses on education.

\section{ERA, 'New Labour' and the Politics of Education in the UK}

In order to better understand how surveillance practices have been legitimated over time, it is first necessary to focus on contemporary education policy developments.

The 1988 Education Reform Act (ERA) was arguably hailed as the most influential piece of education legislation since the 1944 Education Act (Maclure, 1988). If the 1944 act mirrored an underpinning ideology of liberal democracy, then the 1988 Act reflected the Conservative Government's commitment to a New Right ideology, which was a fusion of neo-liberalism and neo-conservatism. As Tomlinson (2001:46) suggests:

It made the decisive break with welfare state principles (and) in contrast was about individual entrepreneurism and competitiveness, achieved through bringing education into the marketplace by consumer choice...It was also paradoxically about increasing the influence of the central state on education by reducing local powers and taking control of what was taught in schools.

The key features of the Act were as follows:

- It gave parents more choice and control over their children's education

- It increased the power of central government as it relates to education

- It imposed a centrally directed national curriculum

- It introduced a national programme of assessment for children at 7.11,14 and 16

- It eroded the power of Local Education Authorities (LEAs) with the introduction of local management of schools

- It constructed a new category of grant -maintained schools financed directly by central government

- It paved the way for fundamental administrative and financial changes in $\mathrm{HE}$ and FE

During the period 1988-1996, market competition and consumer rights became the driving force behind educational reform. Ranson (1994:77) sums up the strategy for reform thus: "parent power in a market place of schools that are made more accountable to their consumers would improve educational standards". The concept of competition was further embedded via the 1992 Education (Schools) Act and the 1993 Education (Schools Inspection) Regulations which set up the Office for Standards in Education (OFSTED). Failing schools could now be readily identified and parents as consumers could choose the best 'educational products' for their children. 
Since 1997, Tony Blair's political rhetoric of 'education, education and education' has been the centrepiece of 'New Labour' whereby, 'The key to a successful economy was to be knowledge and education" (Tomlinson, 2001:88). Like the previous Conservative administration, "New Labour" has articulated moves to enforce a privatised educational economy. The common ideological aims of both neo-liberalism and the "third way" have been to transfer financial responsibility for children's educational provision away from the state and to schools and individual families (Powell and Edwards, 2003). Over the past few years, the problem of 'parental choice' had reached salience at a time when the matrix relationship between the State, education and the economy was being restructured. Coupled with this, educational policy initiatives such as ERA have a number of common threads that establish both a shift in pupils teaching and learning needs and the surveillance of teachers and those pupils being taught.

Increased surveillance is often presented in official educational policy as a tactical response to crises at the margins of education policy, the accidental accretion of responses to unintended consequences. The argument pursued here, however, suggests that increased surveillance is part of the strategic agenda of wider social context of morality and control without which the technology surrounding education fails to make sense to those employed to use and facilitate it.

The rest of the paper will explore issues in a number of ways. First, concepts of surveillance, discourse and power drawn from the work of Michel Foucault (1977) will be used to expand upon discontinuities between ERA and its consequences. Second, the paper questions morality in order to highlight change and the educational technology available to execute it, namely, schooling practices. Finally, the relationship between overt concerns and covert consequences will be analysed in order to examine how benevolent intentions, without critical analysis, can result in negative outcomes for the pupils of state education.

\section{Foucault and the Surveillance Culture}

The critical work of Michel Foucault has engendered an awareness that modern institutions operate according to logics that are often at excessive variance with the humanist visions embedded in policy analysis (Penna and O'Brien, 1998:51). In other words, the overt meanings given to a certain policy of activity may not correspond to their consequences. Whether these outcomes are intended or accidental was less important to Foucault than the analysis of power. As Smart (1985:77) points out, Foucauldian analysis asks of power: "how is it exercised; by what means?" and second, "what are the effects of the exercise of power?" Within those strategies, investigation would need to be centred on the mechanisms, the 'technologies' employed and to the consequences of any social momentum for change.

An example of the discordance between education policy, the philosophy that overtly drove a certain initiative and its effects, comes from Foucault's (1977:201) analysis of utilitarianism. Indeed, a pervasive theme of Foucault's (1977) work is the way in which the Panopticon "would make it possible for a single gaze to see everything perfectly" (1977:173). Foucault describes how panopticism (based on the design of philosopher and penal architect Jeremy Bentham) becomes a process whereby certain mechanisms permeate social systems beyond actual, 
physical institutions. Techniques are thus "broken down into flexible methods of control, which may be transferred and adapted ... (as)... centres of observation disseminated throughout society" (1977: 211-2).

The mechanisms used to extend the reach of centres of power will vary depending upon the ground upon which they are required to operate. Their function is to evoke and sustain moral interpretations of particular social behaviours throughout intermittent observation such that their objects come to internalise their own surveillance.

One important facet of Foucault's analysis is the author's preoccupation with historical periods in which conventional values are in flux as in the case of madness, discipline and sexuality (Foucault, 1977) and how the emergence of professional discourses interpenetrate the evolution of new commonsensical understandings of 'normality'. There are, in other words, periods in which particular sites of control, for example, educational provision is subject to novel mechanisms and technologies in order to facilitate the transition from one state of affairs to another.

These technologies may be overtly applied during periods of flux until moral relations have been accepted, and, during the process of their application they both modify and are modified by the professional groupings, such as teachers, charged with their implementation. While Foucault does not impose any sense of causality on the development of such discourses, it is possible to discern the need for both an explicit moral reason and a method of operation, shaped to whatever new contexts are appropriate. Government morality would act as a legitimacy function for activities such as surveillance. A professional technology would provide a means of implementation depending upon the site (for example, in institutions of the state) of the targeted activity.

An examination of the relationship between 'power' and 'knowledge' is central in order to interpret and understand social phenomena through a Foucauldian gaze (Rouse, 1994). This is particularly apposite where there is an attempt at disaggregation of a stated policy and its mechanisms in order to discover what is thereby hidden. One of the consequences of power/knowledge is that rather than focusing on the explicit use of a particular technique of knowledge by someone in power to cause a certain effect, attention is drawn to the reflexive relationship between both elements. There is a concern then:

with the epistemic context within which those bodies of knowledge become intelligible and authoritative. How statements were organised thematically, which of those statements counted as serious, who was empowered to speak seriously, and what questions and procedures were relevant to assess the credibility of those statements that were taken seriously. (Rouse 1994, 93).

Just as knowledge shapes what action is possible, what power is exercised, those actions shape the creation of new knowledge and what is thereby given credence. Over ime legitimate 'domains' are established which both define what is real and what can be done about it. Other possible interpretations are simultaneously discounted and delegitimised. The result is a self- 
contained commonsense world in which power and knowledge support each other. These domains, for example, not only sustain certain professional discourses, they mould what those professions might become. This analysis of power and knowledge emphasises their entwinement and the processes that occur as a particular domain takes shape. It also highlights the distinction between what a method for obtaining knowledge produces, and the relationship between the shaping of that product and the distribution of power. As Foucault $(1982,86)$ indicated, "power is tolerable only on condition that it masks a substantial part of itself. Its success is proportional to its ability to hide its own mechanisms".

In the education system the overt intention to 'empower' by allowing students to identify and monitor their learning needs and achievements may have become a means of policing education and through it the conduct of pupils. Throughout the 1980s and 1990s educational policy has drawn upon a number of sources of flux to maintain momentum. These have included a concern over familial obligation to schooling, changing teaching practices and the transfer of the traditional head teacher role to that of professional and financial manager.

\section{Morality and Education: Family Values}

The implementation of ERA occurred at the same time as wider policy and moral initiatives on the 'family' and its relationship to education. As Jordan (1995) has observed, similar to New Labour's 'family values' discourse, the Major administration's (1992-4) 'back to basics' campaign signalled a change in the logic of social policy as individualist and moral discourses were deployed to justify new arrangements of choice in education. It "represents a recognition that markets and families do not provide self-enforcing order under the social conditions that government policy has created" (Jordan 1995:371). In addition, the Blair Government (1997- ) claims that education itself is to be treated as cost-effective by budget developers and holders. The 'no-cost' option of a social policy reliant on school's own self-governance comes to look increasingly fragile. It is, therefore, a shift to the moral ground of 'partnerships' and 'community obligation' that the Blair Administration now strives.

Thus, an educational policy exists that contains fiscal elements and morality and makes inequality in schools a legitimate responsibility and differential attainment provides the excuse for an invasion of 'league tables' (Powell and Edwards, 2002). However, to be fully effective, a technology would also need to be found that would implement the logic of this policy.

\section{Technologies of Power: Head Teachers as Budget Manager}

The core technology by which education can be implemented exists in the role of head teachers as budget managers. Policy guidance to head management first appeared in the ERA. Head management can be conceptualised as the co-ordination of education into a 'package of budget provision' (Powell and Edwards, 2003) in order to manage human and financial resources in schools. The managerial technology is indirect in two ways. First, the pivotal function of the head teacher is seen as being the management of school that draws on teachers made available 
through a 'supply market'. Second, there is the emphasis on assessment and monitoring of provisions supplied by teachers via quality control and assurance mechanisms.

This quality of indirectness 'makes sense' as a means of managing a school that requires that those who purchase learning materials, or their educational agents, be separated from those who provide it. Because of the intensification of marketisation, this limits the development of cartels, allow purchasers to choose between competing alternatives. Thus placing them in the role of 'honest brokers' who assess learning needs, supply information on the alternatives and then coordinate purchases. It does not make sense in terms of direct education i.e. intervention or interaction between pupils, families and teachers: other than as a sort of 'professional travel agency', advising families on the cash options, best deals and choice. Educational assessment and monitoring have now become integral features of teaching practice and reflect a trend toward justifying welfare activities in terms of quality assurance.

The Department of Education and Skills has commissioned research into demonstration projects in order to monitor the implementation of Head management (Powell and Edwards, 2003). Unsurprisingly, this programme has generated scarce critical analysis of the role of this technology of education, focusing, instead, on the financial success achieved in its adoption. By replacing direct intervention with management systems, the technology fails to provide guiding theoretical principles for interpreting and acting on conflict in social relationships within schools.

Under 'New Labour' the shift in the focus of educational assessment and school inspection contains a number of re-alignments. First, assessment decisions seem to be taking place within an existing discourse on differential educational achievement rather than pupil substantive learning needs. Second, the focus of monitoring seems to have moved from the performance of elements of the pupil's learning development to the 'conduct of conduct' (Foucault 1977) of pupils and their families.

There is also no mention of new services that might be used to intervene in cases where poor attainment has been identified except to name and shame schools through use of league tables (Powell and Edwards, 2003) where children are under performing. It would seem that the primary role of the state is thus to observe and construct evidence, but not to intervene in pupils' educational needs.

\section{The Panoptic Educational Culture}

Why is educational policy such as ERA that is essentially empty of interpersonal meaning "legitimised" by the accretion of surveillance? The answer to this measure lies in the fact that it was not created as a philanthropic metaphor but as a mechanism for engineering the cost and structure of education (Powell and Edwards, 2002). Education has been part of a strategy to reduce the costs of state welfare by adopting market principles (Hoyle and Le Grand, 1991). Attempts at cost reduction have taken on two forms. First, there is the active encouragement of a private education in order to depress public costs. Secondly, a process of hollowing out the local state takes place through mechanisms such as managerialism and inspection. These trends 
may not simply reflect a flow through from market ideology but also wider pressure on the nation state as a consequence of globalization (Dominelli and Hoogvelt, 1996).

Awareness that the welfare state can be understood not so much as a series of educational institutions and neo-liberal responses to social problems, but as an instrument of wider state power and governance, is not new (Jessop, 1994). Until the advent of a panoptic culture instigated by ERA, education policy lacked a convincing unifying metaphor for its activity. With its instigation, a previously inchoate accretion of initiatives around education achieves harmony and force. Once the vigilance advocated by the Department of Education and Employment's guidelines on education are added to the indirect functioning of head teaching technology and the moral backdrop of familial obligation, the discourse of education acquires a coherence of power/knowledge. It is, however, a power/knowledge to be deployed against pupils, families and teacher's voices rather than for their emancipation.

\section{Critical reflection and future research}

There are several important questions that need to be raised, if the full complexity of the processes surrounding ERA, morality and relevance of Foucauldian theory are to be appreciated and understood. Specifically, the issues of critical pessimism and a Foucault-Marxist duality need to be addressed.

One of the major criticisms of Foucauldian theory centres on critical pessimism. Indeed, there is no recipe offered for social transformation or social change. As Shumway (1989:158) points out, a Foucauldian approach "does little to encourage or instruct anyone interested in undertaking such action". In addition, Foucault "gives the impression that resistance is generally contained by power and poses no threat" (Fairclough, 1992: 57).

Smart (1985) argues that scholars may care to ponder synthesising Foucauldian and neoMarxist approaches. There remain many un-resolved political tensions between Foucault and Marxist thought. Indeed, Alan Walker $(1981,74)$ asks the question "is not the class structure a key determinant of the position of individuals in capitalist society?". The implication is society itself makes it very difficult for 'resistance' when population groups are de-commodified (Powell and Edwards, 2003). In addition, Foucault's notion of surveillance is problematic itself. A reflective critique is that the Foucauldian use of surveillance of subjects/objects of education such as pupils and families, fails to relate such practices to wider social class interests which, according to Phillipson (1998), motivate policy development in social welfare such as education. Further, a Foucauldian perspective does not pay much particular attention to sociological fault lines of "race", sexuality, disability and gender and how they are blurred and positioned by neoliberalism.

This paper has revealed that Foucauldian accounts of systems of surveillance, knowledge and social processes can provide a rich seam of theorizing about education and morality. Two questions are flagged up: what other explanations does the assessment of disciplinary and policy discourses tell us about education? What are the lessons for future research? 
First, we are alerted to the partial nature of the discourses supplied by systems of knowledge and social processes, which affects perceptions of education. The simplifying role of policy discourse tends to highlight certain, politically valued, aspects of experience to the exclusion of other possibilities. Moreover, policy development is uneven and subject to elision, which means that it is quite possible for different, even conflicting and neo-liberal and social democratic discourses of education to coexist in different parts of the policy system. Policy discourses share a deep coherence, which may help $\mathfrak{b}$ explain their co-existence: each download 'risk' and 'responsibility' onto educational objects/subjects.

Second, a significant element in the 'riskiness' (Bauman, 1992; Powell and Edwards, 2003) of building 'the self' under contemporary conditions may arise from the existence of multiple policy discourses that personal narratives of self have to negotiate. Future research on the intrasubjectivities of identity, should, then, be sensitised to the multiple grounds on which identity might be built and the potential sources of educational policy and professional conflict and uncertainty that this may bring.

Finally, attention should be paid to the multiple sources for building narratives "to live by" (Powell and Edwards, 2002:4) and the tension between legitimising policy discourses and alternative technologies of self. Indeed in a future of complex and multiple educational policy agendas, it would appear that a narrative of 'social inclusion' through consumerism could coexist with one emphasising managerial surveillance of objects/subjects of power/knowledge.

\section{Conclusion}

This paper has explored a disturbing constellation of factors in educational policy and rhetoric in the UK. It has been argued that the 'discovery' of differential educational attainment has lent coherence to a number of nascent tendencies in this policy that reinforce each other. These tendencies include an increased moralism toward pupils and a move toward indirect monitoring of the locative sites of such education. The development of a surveillance culture helps stabilise policy such as ERA at a time of considerable underlying uncertainty. Such uncertainty has arisen from the changing structure of education and of specific schools (Powell and Edwards, 2003). The neo-liberal strategy, to socialise, has become an extension of the techniques of observation, monitoring and control into school settings. A new system for the surveillance of pupils, families and teachers has replaced the idealistic dream of freedom of learning with an extension of constraint.

Following Foucault's (1977) analysis of the relationship between power and knowledge, this change can be seen as the development of a matrix in which to speak seriously about the support of pupils learning needs, the employment of discourse of surveillance would have to be entailed. It serves to reconfigure power relations during a period of flux and 'makes sense' of a previously disjointed policy formulation such as ERA. Schooling has thus filled a vacuum at the centre of education policy with potentially harmful consequences for pupils as learning entails surveillance and consent contains the threat of coercion. The powerful language of surveillance offers a form of universalism to social and educational policy (Chua, 1995), which, as Williams (1992) has 
pointed out, has been subject to "fragmentation, change and uncertainty and contradiction" (1992:200). It is within the disciplinary duality of 'surveillance' and 'normalization' which power operates, over the identities of pupils and families, ultimately reinforcing the segmentation that surveillance gives rise to at the centre of both policy and professional gazes.

\section{References}

Ball, S. (ed.) (1990) Foucault and Education: Discipline and Knowledge. London: Routledge

Bauman, Z. (1992) Imitations of Postmodernity, London: Routledge.

Bowles, S. and H. Gintis, (1976) Schooling in Capitalist America, RKP: London.

Chau, W.F (1995) 'Experts, networks and inscriptions in the fabrication of accounting images,'Accounting Organisations and Society, 20(2/3): 111-145.

Culpitt, I (1992) Welfare and Citizenship, London: Sage.

Davidson, A (1986) ‘Archaeology, Genealogy, Ethics', in D. Hoy (ed.) Foucault: a critical reader, Oxford: Basil Blackwell.

Dominelli, L and Hoogvelt, A (1996) 'Globalisation and the technocratisation of social work,' Critical Social Policy, 16(2): 45-62.

Fairclough, N. (1992) Discourse and Social Change, Cambridge: Polity.

Foucault, M. (1965) Madness and Civilization, London: Tavistock.

Foucault, M. (1977) Discipline and Punish, London: Penguin.

Foucault, M. (1978) The History of Sexuality, Vol.1, London: Penguin.

Foucault, M. (1982) 'The subject of Power'’ in H. Dreyfus and P. Rabinow (eds.) Michel Foucault: Beyond Structuralism and Hermeneutics, Brighton: Harvester.

Foucault, M. (1991) 'Governmentality,' in G. Burchell (ed.) The Foucault Effect: Studies in Governmentality, Chicago: University of Chicago Press.

Granovetter, M (1985) 'Economic action and social structure -the problem of embeddedness,' American Journal of Sociology, 91(3): 481-510.

Granovetter, M.(1992) 'Economic Institutions as social constructions,' Acta Sociologica, 25(3): 3-11.

Hoyle, L and J. Le Grand (1991) Markets in Social Care Services, Bristol: SAUS.

Jessop, B. (1994) 'The Transition to post-fordism and the Schumpeterian workfare state,' in R. Burrows and B. Loader (eds.) Towards a Post-Fordist Welfare State?, London: Routledge.

Jordan, B. (1995) 'Are new right policies sustainable? Back to Basics and Public Choice,' Journal of Social Policy, 24(3): 363-384.

Maclure, S. (1988) Education Re-formed, London: Hodder and Stoughton.

Mills, C.W. (1959) The Sociological Imagination, Basic Books: New York. 
Penna, S and M. O’Brien (1998) Theorising Welfare Enlightenment and Modern Society, London: Sage.

Phillipson, C. (1998) Reconstructing Old Age, Sage: London.

Powell, J.L. and M. M. Edwards (2002) 'Policy Narratives of Aging: The Third Way, The Right Way or the Wrong Way', Electronic Journal of Sociology, 6(1): 1-10

Powell, J.L. and M. M. Edwards (2003) 'Risk and Youth: A Critical Sociological Narrative', International Journal of Sociology and Social Policy, 23(12): 81-95

Ranson, S. (1994) Towards a Learning Society, London: Cassell.

Rose, N. (1999) 'Government, authority and expertise in advanced liberalism,' Economy and Society, 22(3): 283-99.

Rouse, J. (1994) 'Power/Knowledge' in G. Gutting (ed.) The Cambridge Companion to Foucault, Cambridge: Cambridge University Press.

Shumway, D. (1989) Michel Foucault, Charlottesville: University of Virginia Press.

Smart, B. (1985) Michel Foucault, London: Routledge.

Tomlinson, S. (2001) Education in a Post-Welfare Society, Buckingham: Open University Press.

Veyne, P.(1980) Foucault revolutionne l'histoire, Paris.

Walker, A. (1981) 'Towards a Political Economy of Old Age,' Ageing and Society, 1: 73-94.

Williams, F. (1992) 'Somewhere over the rainbow: universality and diversity in social policy,' in N. Manning and R. Page (e ds.) Social Policy Review 4, Canterbury: SPA. 